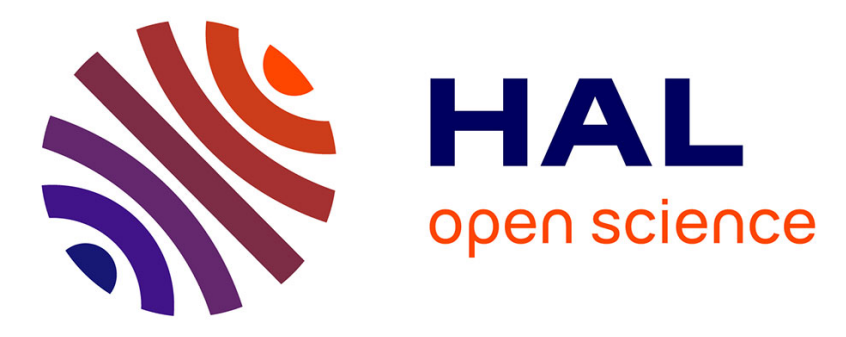

\title{
Fragmentation processes in polystyrene films under sliding conditions
}

Antoine Chateauminois, Marie-Christine Baietto, Christian Gauthier, Robert Schirrer

\section{- To cite this version:}

Antoine Chateauminois, Marie-Christine Baietto, Christian Gauthier, Robert Schirrer. Fragmentation processes in polystyrene films under sliding conditions. World Tribology Congress III, Sep 2005, Washington, United States. 10.1115/WTC2005-63493 . hal-01951820

\section{HAL Id: hal-01951820 \\ https://hal.science/hal-01951820}

Submitted on 6 Jul 2021

HAL is a multi-disciplinary open access archive for the deposit and dissemination of scientific research documents, whether they are published or not. The documents may come from teaching and research institutions in France or abroad, or from public or private research centers.
L'archive ouverte pluridisciplinaire HAL, est destinée au dépôt et à la diffusion de documents scientifiques de niveau recherche, publiés ou non, émanant des établissements d'enseignement et de recherche français ou étrangers, des laboratoires publics ou privés.

\section{(c)(1)}

Distributed under a Creative Commons Attribution| 4.0 International License 


\title{
FRAGMENTATION PROCESSES IN POLYSTYRENE FILMS UNDER SLIDING CONDITIONS.
}

\author{
A. Chateauminois ${ }^{1 \ddagger}$, M.C. Baietto-Dubourg ${ }^{2}$, \\ C. Gauthier ${ }^{3}$ and R. Schirrer ${ }^{3}$ \\ 1‡. Laboratoire de Physico-Chimie des Polymères et des \\ Milieux Dispersés, UMR 7615, Ecole Supérieure de \\ Physique et de Chimie Industrielles (ESPCI), 10 rue \\ Vauquelin , 75231 Paris Cedex 05, France \\ 2. Laboratoire de Mécanique des Contacts et du Solide, \\ UMR 5514, INSA de Lyon, 18-20, rue des Sciences, \\ F69621 Villeurbanne Cedex, France \\ 3. Institut Charles Sadron, UPR 226, rue Boussingault, F- \\ 67083 Strasbourg, France Paris Cedex 05, France
}

\begin{abstract}
Fracture processes of thin $(10-100 \mu \mathrm{m})$ polystyrene films on PMMA substrates have been investigated within macroscopic single-asperity sliding contacts with rigid spherical counterfaces. Using the resources of in situ contact visualisation, the development of cracks has been analysed for various values of the ratio of the contact radius to the film thickness. Damage mechanisms were dominated by the formation of a network of regularly spaced cracks at the leading edge of the contact. These processes were analysed in the light of a fragmentation model based on contact mechanics simulations of the stress field induced within cracked films. It emerged from the simulations that the mean spacing between adjacent cracks can be correlated to the strength of the polymer coating.
\end{abstract}

\section{INTRODUCTION}

During the scratching of polymer coatings, regular crack patterns are often observed at the leading edge of the contacts. A critical normal force is often ascribed to the occurrence of these processes, but the way it relates to known polymer failure properties such as fracture toughness is still a matter of debate. In addition, the contribution of substrate deformation to the development of contact cracks within thin polymer films remains largely unknown. As a first approach, the magnitude of these effects may be assumed to depend largely on the ratio of the contact radius, $a$, to the film thickness, $h$. In many contact situations, this $\mathrm{a} / \mathrm{h}$ ratio can vary by orders of magnitude depending on whether the macroscopic or micro-asperity contact lengths are considered. There is therefore a need for a better understanding of coating fracture processes as a function of this characteristic $a / h$ ratio.

Within the frame of this investigation, fracture mechanisms of thin (10-100 $\mu \mathrm{m})$ polystyrene (PS) films on polymethylmethacrylate (PMMA) substrates have been investigated within macroscopic sliding contacts with smooth spherical asperities. Using the resources of in situ contact visualization, the various stages of the development of crack networks within the PS film have been observed for a range of of $a / h$ ratios. The resulting crack patterns have been analyzed in the light of a fragmentation model which considers that failure is driven by the evolving tensile stress field induced within the cracked PS film at the leading edge of the contact. For that purpose, a contact mechanics analysis of the cracked coated systems has been developed which is able to simulate the film unloading/reloading processes associated with the successive propagation of cracks during sliding.

\section{RESULTS AND DISCUSSION}

Under predominantly elastic conditions, the film damage mechanisms were dominated by the formation of a network of regularly spaced cracks at the leading edge of the contact under the action of predominantly tensile stresses. No cracks were observed in the PMMA substrate. The critical fragmentation lengths associated with the failure of the PS coating were found to depend on the film thickness and on the contact radius. 
However, all the experimental data rescaled on a single relationship when the normalized critical length, $L_{c} / h$, was plotted as a function of the normalized contact radius, $a / h$. These observations were rationalized by considering that the fragmentation of the polystyrene films was controlled by a succession of tensile loading and unloading events which were induced by the sliding and film failure processes, respectively.

In order to validate these hypotheses, numerical simulations have been carried out using a contact model developed by Dubourg et al [1] which incorporates linear fracture mechanics ingredients. The specificity of the model is to allow the calculation of stress fields and stress intensity factors within contacts containing a distribution of cracks of given lengths, orientations and locations.

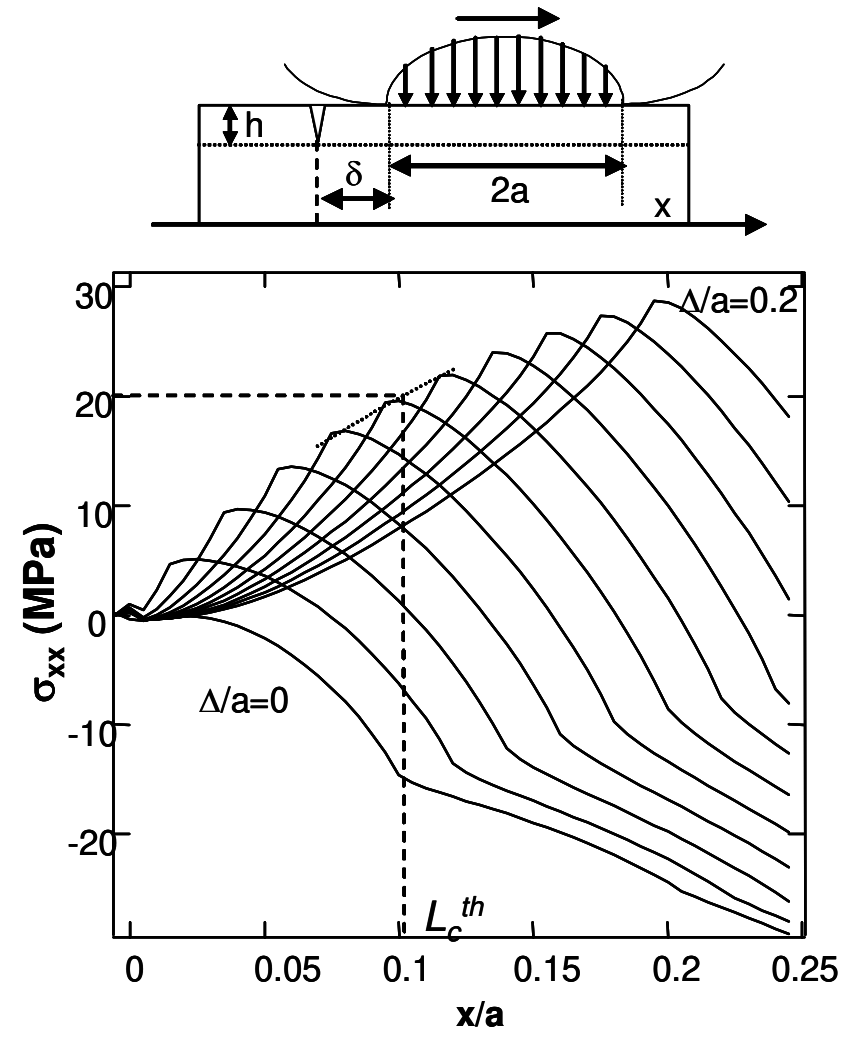

Figure 1. Calculated surface tensile stress profiles for increasing values of the normalized distance, $\Delta=\delta / h$, between the crack and the leading edge of the contact $(a / h=2)$. The increment of the normalized displacement between two successive profiles is $2 \times 10-2$. The figure shows an example of the determination of the critical reloading length, $L_{c}^{\text {th }}$, assuming that the strength of the coating is $20 \mathrm{MPa}$.

Within the frame of this investigation, simulations were carried out assuming that the coating cracks were straight cracks oriented perpendicular with respect to the surface.

The profiles of the surface tensile stress in the vicinity of a crack have been calculated for different values of the sliding distance with respect to the contact radius. For moderate $a / h$ $(a / h \sim 1)$, the profiles are characterized by the existence of a peak stress whose location corresponds to the leading edge of the contact, similarly to what would be calculated for an uncracked Hertzian contact (Fig.1). However, the magnitude of this tensile peak stress is much lower than that for an uncracked substrate. This lowered peak stress illustrates the strong relaxation of the coating stresses which results from crack opening processes. When the sliding distance is increased, the tensile reloading of the film is indicated by the progressive increase in the peak stress. Accordingly, a critical length, $L_{c}^{\text {th }}$, can be defined as the distance relative to the crack location where the peak tensile stress reaches the failure strength of the PS coating. For higher $a / h$ ratio (i.e. $a / h>10$ ), the unloading processes associated with the opening of the crack are insufficient to lower the coating tensile stresses below known values of the failure strength of polystyrene. In other words, the simulation indicates that multiple tensile cracks should be nucleated simultaneously close to the leading edge of the contact when the contact radius becomes much larger than the coating thickness. Such processes were found to be consistent with experimental observations.

In Fig. 2, the theoretical normalized critical lengths, $L_{c}^{\text {th }} / h$, have been reported as a function of $a / h$ assuming three different values of the coating failure stress, namely 10, 20 and $30 \mathrm{MPa}$. Whatever the value of this strength criterion, the curves show distinctly a saturation of the critical length at high a/h ratios. The existence of such a saturation process can be related to the fact that the calculated stress gradient in the vicinity of the crack remains unaffected by its depth above some critical $a / h$ value. The shaded area in Fig. 2 corresponds to experimental data band reported. It can be noted that theoretical data are very consistent with the experimental ones if the failure strength of the film is set to $30 \mathrm{MPa}$, i.e. a value close to the acknowledged crazing stress of PS. Such a result supports on a quantitative basis the potential assessment of the strength of a polymer coating from fragmentation experiments carried out under sliding conditions.

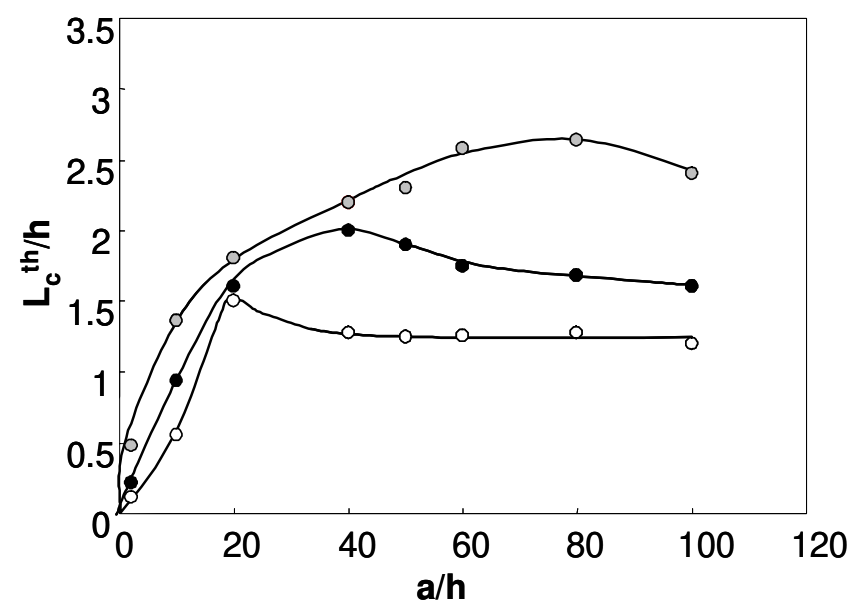

Figure 1. Theoretical values of the normalized critical length, $L_{c}^{\text {th }} / h$, as a function of the normalized contact radius, $a / h$. The three curves were obtained assuming different strength failure criteria for the polystyrene layer: (O) $10 \mathrm{MPa},(\mathrm{O}) 20 \mathrm{MPa},(\mathrm{O}) 30 \mathrm{MPa}$. The dashed grey area corresponds to experimental data.

\section{REFERENCES}

1. Dubourg, M.C. and Villechaise, B. ASME J Tribology, 1992, 114, 455-461 